\title{
Critical role of nitric oxide-cGMP cascade in the formation of cAMP-dependent long-term memory
}

\author{
Yukihisa Matsumoto, ${ }^{1}$ Sae Unoki, ${ }^{1}$ Hitoshi Aonuma, ${ }^{2}$ and Makoto Mizunami ${ }^{1,3}$ \\ ${ }^{1}$ Graduate School of Life Sciences, Tohoku University, Katahira 2-1-1, Aoba-ku, Sendai 980-8577, Japan; ${ }^{2}$ Research Institute \\ for Electronic Science, Hokkaido University, Sapporo 060-0812, Japan
}

\begin{abstract}
Cyclic AMP pathway plays an essential role in formation of long-term memory (LTM). In some species, the nitric oxide (NO)-cyclic GMP pathway has been found to act in parallel and complementary to the cAMP pathway for LTM formation. Here we describe a new role of the NO-cGMP pathway, namely, stimulation of the CAMP pathway to induce LTM. We have studied the signaling cascade underlying LTM formation by systematically coinjecting various "LTM-inducing" and "LTM-blocking" drugs in crickets. Multiple-trial olfactory conditioning led to LTM that lasted for several days, while memory induced by single-trial conditioning decayed away within several hours. Injection of inhibitors of the enzyme forming NO, CGMP, or cAMP into the hemolymph prior to multiple-trial conditioning blocked LTM, whereas injection of an NO donor, cGMP analog, or cAMP analog prior to single-trial conditioning induced LTM. Induction of LTM by injection of an NO donor or cGMP analog paired with single-trial conditioning was blocked by inhibitors of the cAMP pathway, but induction of LTM by a cAMP analog was unaffected by inhibitors of the NO-cGMP pathway. Inhibitors of cyclic nucleotide-gated channel (CNG channel) or calmodulin-blocked induction of LTM by cGMP analog paired with single-trial conditioning, but they did not affect induction of LTM by CAMP analog. Our findings suggest that the CAMP pathway is a downstream target of the NO-cGMP pathway for the formation of LTM, and that the CNG channel and calcium-calmodulin intervene between the NO-cGMP pathway and the cAMP pathway.
\end{abstract}

In both vertebrates and invertebrates, nervous systems store information for short-term memory (STM) and long-term memory (LTM) by changing the strength of their synaptic connections (Kandel 2001). Studies in many species, including mollusca Aplysia, fruitflies Drosophila, and mice, suggest that STM storage is accompanied by transient changes in the strength of synaptic connections by covalent modifications of pre-existing proteins and that LTM storage, in contrast, is accompanied by enduring changes in synaptic strength that require transcription and translation of genes (Montarolo et al. 1986; DeZazzo and Tully 1995). In all of these species, formation of LTM requires an increase in intracellular cAMP and recruitment of the cAMP-dependent protein kinase (PKA) that phosphorylates the transcription factor, cAMP-responsive element-binding protein (CREB) (Bartsch et al. 1995; Yin et al. 1995; Abel et al. 1997).

The roles of the cAMP pathway in the formation of LTM are often supplemented by other signaling pathways, most notably by the nitric oxide (NO)-cGMP signaling pathway (Lewin and Walters 1999; Lu et al. 1999). NO is a membrane-permeable molecule that functions in intercellular signaling in the brain (Garthwaite et al. 1988). In mice, NO contributes to late-phase longterm potentiation of synaptic transmission by stimulating soluble guanylate cyclase in target cells, and the resulting increase in cGMP concentration stimulates cGMP-dependent protein kinase (PKG), which acts in parallel with PKA to increase the phosphorylation of CREB (Lu et al. 1999). In nociceptive sensory neurons of Aplysia, the induction of long-term hyper-excitability after a noxious stimulus depends on the NO-cGMP-PKG pathway, which acts in parallel with the cAMP-PKA pathway (Lewin and Walters 1999). In associative olfactory learning in honey bees, it has been shown that prolonged PKA activation in the

\footnotetext{
${ }^{3}$ Corresponding author.

E-mail makoto@biology.tohoku.ac.jp; fax 81-22-217-5050.

Article and publication are at http://www.learnmem.org/cgi/doi/10.1101/ Im.130506.
}

antennal lobe (primary olfactory center) mediated by the NOcGMP pathway is critical for LTM induction (Müller 1996, 2000) and it has been speculated that PKA is activated by either cAMP or cGMP and thus, the cAMP pathway and NO-cGMP pathway act in parallel to activate PKA, although this hypothesis remains to be tested. Histochemical studies of the brains of various insect species (Müller and Bicker 1994; Bicker 2001) have suggested that NO synthase is distributed in the antennal lobe and the mushroom body, both centers implicated in olfactory learning and memory (Erber et al. 1980; Hammer and Menzel 1998).

In crickets, we examined the biochemical pathway involved in the formation of LTM in associative olfactory learning. These animals are newly emerging subjects for the study of learning and memory. Crickets are capable of quickly learning olfactory signals and memorizing them for practically a lifetime (Matsumoto and Mizunami 2000, 2002b, 2004), and they can be easily used for detailed pharmacological (Matsumoto et al. 2003; Unoki et al. 2005) and electrophysiological (Paydar et al. 1999) studies as well as for RNAi analysis (Miyawaki et al. 2004). Our results indicate that sequential activation of the NO-cGMP signaling pathway, cyclic nucleotide-gated anion channel, calciumcalmodulin, and then the cAMP-PKA pathway, induces protein synthesis-dependent LTM, thereby demonstrating a new role of the NO-cGMP pathway, namely, induction of LTM by activating the cAMP pathway.

\section{Results}

Formation of LTM by multiple-trial conditioning

At first, we compared memory retention after single- and multiple-trial olfactory conditioning in crickets. Crickets in seven groups were each subjected to a single appetitive conditioning trial in which peppermint odor was associated with a water reward. Odor preferences of the crickets were tested before and at various times after training by letting them choose between reward-associated odor (peppermint) and control odor (vanilla). 
Before conditioning, the animals exhibited significantly greater preference for vanilla odor over peppermint odor (Matsumoto and Mizunami 2002a). At $30 \mathrm{~min}$ after conditioning, the animals exhibited significantly increased preference for reward-associated odor compared with preferences before the conditioning (Fig. 1) (Statistical results are shown in legends). Unpaired presentation of odor and water did not induce a change of odor preference (Matsumoto and Mizunami 2002a). Thus, a single trial is sufficient to achieve conditioning. The level of memory retention, however, decreased during the next several hours, with no significant level of memory retention at $8 \mathrm{~h}$ after conditioning.

Animals in another four groups were each subjected to two appetitive conditioning trials and two aversive conditioning trials given in an alternative sequence with an intertrial interval of $5 \mathrm{~min}$; for the latter trial, vanilla odor was associated with saline solution. We used this four-trial differential conditioning procedure, not four-trial appetitive conditioning procedure, since the former procedure induces a higher level of long-term $(24 \mathrm{~h})$ retention compared with the latter procedure (Matsumoto and Mizunami 2002a), and thus, the effect of inhibitors can be studied more easily. The odor preferences of the animals were tested before and at various times after conditioning. The animals subjected to four-trial differential conditioning exhibited no significant decay of memory retention from 30 min to $24 \mathrm{~h}$ after conditioning (Fig. 1). Memory formed by multiple-trial differential conditioning lasted for at least $4 \mathrm{~d}$ without any significant decrement (Matsumoto and Mizunami 2002a) and was sensitive to cycloheximide, a protein-synthesis blocker (Matsumoto et al. 2003). This memory component is referred to as long-term memory (LTM).

\section{Impairment of LTM formation by inhibitors of the NO-cGMP or cAMP pathways}

In order to study the effect of a competitive inhibitor of NO synthase, L-NAME (Müller 1996), animals were each injected with $3 \mu \mathrm{L}$ of saline containing $400 \mu \mathrm{M}$ L-NAME into the head hemolymph at $20 \mathrm{~min}$ prior to multiple-trial conditioning. Con-

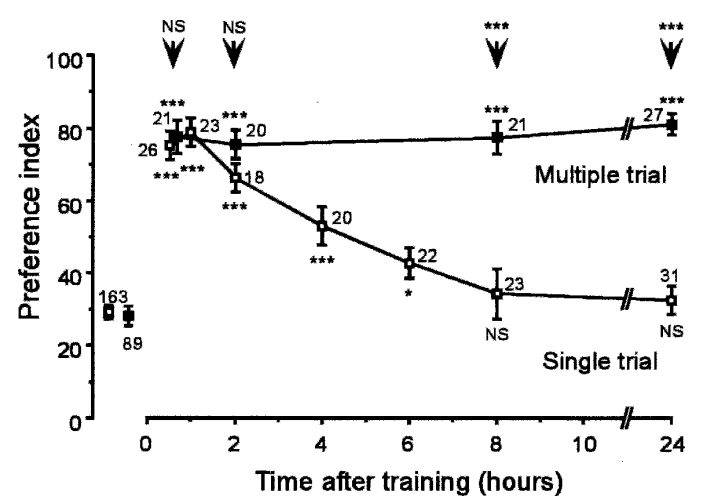

Figure 1. Memory retention after single- and multiple-trial conditioning. Seven animal groups were subjected to single-trial conditioning ( $\square$ ) and another four groups were subjected to multiple-trial conditioning (घ). Odor preference tests were given to all animals before and at various times after conditioning. Preference indexes (PIs) for rewarded odor are shown as means \pm SE. To simplify the figure, the Pls before conditioning are shown as pooled data from seven single-trial or four multiple-trial groups. Statistical comparisons of odor preferences were made before and after conditioning for each group (WCX test) and between singleand multiple-trial groups at each time after conditioning (M-W test), and the results are shown at each data point and above the arrow, respectively. $\left(^{*}\right) P<0.05 ;\left({ }^{* *}\right) P<0.01 ;\left({ }^{* * *}\right) P<0.001$; (NS) $P>0.05$ ). The number of animals is shown at each data point. The preferences for rewarded odor remained unchanged from $30 \mathrm{~min}$ to $24 \mathrm{~h}$ after conditioning in the multiple-trial group $(P>0.05, \mathrm{M}-\mathrm{W}$ test). trol animals were each injected with $400 \mu \mathrm{M}$ D-NAME, an inactive isomer. Animals injected with L-NAME or D-NAME, or any other drugs used in this study, exhibited normal responses to appetitive or aversive stimuli during training. They drank water eagerly and retreated from saline when water or saline was presented to the mouth, as did intact or saline-injected crickets. Drug-injected crickets also exhibited normal locomotory activity and exploration of odor sources during testing. At 30 min or $2 \mathrm{~h}$ after conditioning, the levels of memory retention of L-NAMEinjected animals were not significantly different from those of control animals injected with D-NAME (Fig. 2A). This indicates that L-NAME did not impair (1) sensory and motor functions necessary for normal learning performance, (2) initial acquisition of memory, or (3) memory retention up to $2 \mathrm{~h}$ after conditioning. However, L-NAME-injected animals exhibited a significant decay of memory retention during the next several hours, with no significant levels of memory retention at $6 \mathrm{~h}$ after conditioning (Fig. $2 \mathrm{~A})$. In contrast, the levels of memory retention of D-NAMEinjected animals at $24 \mathrm{~h}$ after conditioning were as high as those at $30 \mathrm{~min}$ after conditioning (Fig. 2A).

The effect of L-NAME was dose dependent. Animals injected with 0.1 or $1 \mu \mathrm{M}$ L-NAME exhibited normal retention at $8 \mathrm{~h}$ after conditioning, those injected with 10 or $100 \mu \mathrm{M}$ L-NAME exhibited significantly decreased levels of 8 -h retention, and those injected with $400 \mu \mathrm{M}$ L-NAME exhibited no significant level of 8-h retention (Fig. 2B). Thus, complete inhibition was attained by injection of $3 \mu \mathrm{L}$ of $400 \mu \mathrm{M}$ L-NAME, which approximately corresponds to a concentration of $1.5 \mu \mathrm{M}$, calculated from the injected volume and the approximate body weight of $850 \mathrm{mg}$. This concentration is comparable to that used to study the effect of L-NAME on LTM in honey bees $(1 \mu \mathrm{M})$ (Müller 1996).

There was an effective time window for L-NAME injection. Animals injected with $3 \mu \mathrm{L}$ of saline containing $400 \mu \mathrm{M}$ L-NAME at 20 or $40 \mathrm{~min}$ prior to conditioning exhibited no significant level of 8-h retention, while those injected at $60 \mathrm{~min}$ before conditioning exhibited significantly decreased levels of 8 -h retention, and those injected at 10 or 90 min prior to conditioning or at 10 min after conditioning exhibited no significant impairment of 8 -h retention (data not shown). The presence of this effective time window indicates that L-NAME interferes with acquisition, not retrieval of memory.

In the following experiments, we routinely injected $3 \mu \mathrm{L}$ of saline containing various drugs at $20 \mathrm{~min}$ prior to conditioning. The effects of all drugs used in this study were dose dependent, but for the sake of simplicity, we describe the effects of drugs only at a concentration at which a maximal inhibitory or facilitatory effect was attained. All drugs were significantly less effective at a concentration 10 times less than that described in this study. We found no significant difference in initial odor preferences among 122 groups of animals used in this study $(P>0.05, \mathrm{~K}-\mathrm{W}$ test). Each group was subjected to odor preference tests before and at a given time after conditioning in order to evaluate retention after conditioning. Efficacy of all drugs used in this study, except for 3,4,-dichlorobenzamil (DCB), has been reported in biochemical or physiological studies in insects, and one or a few representative papers are cited when describing some drugs.

We tested whether the impairment of LTM by L-NAME could be rescued by coinjection of an NO donor, SNAP or NOR3 (Aonuma and Niwa 2004). The levels of 12-h retention of animals coinjected with L-NAME $(400 \mu \mathrm{M})$ and SNAP $(200 \mu \mathrm{M})$ (Fig. 2C, hatched bars) or NOR3 $(10 \mu \mathrm{M})$ (data not shown) were as high as those of 8-h or 24-h retention of D-NAME-injected animals (Fig. 2A). In contrast, no rescue of LTM was observed when degassed SNAP $(200 \mu \mathrm{M})$ was coinjected with L-NAME (Fig. 2C, black bars).

In order to study the effect of an NO scavenger, animals were each injected with $10 \mu \mathrm{M}$ PTIO (Aonuma and Newland 
A
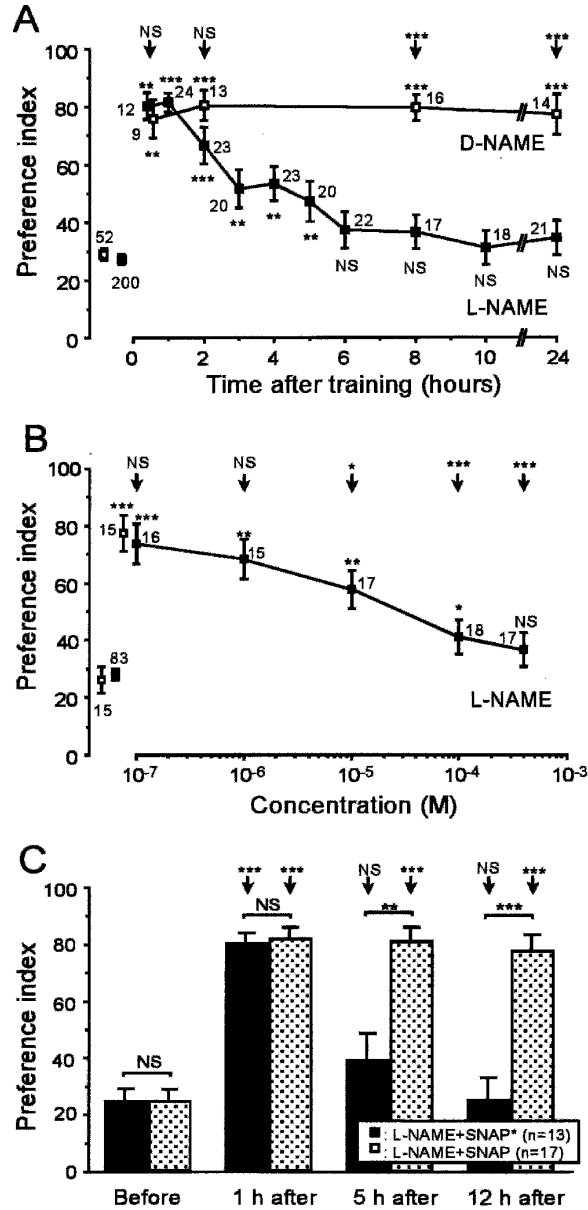
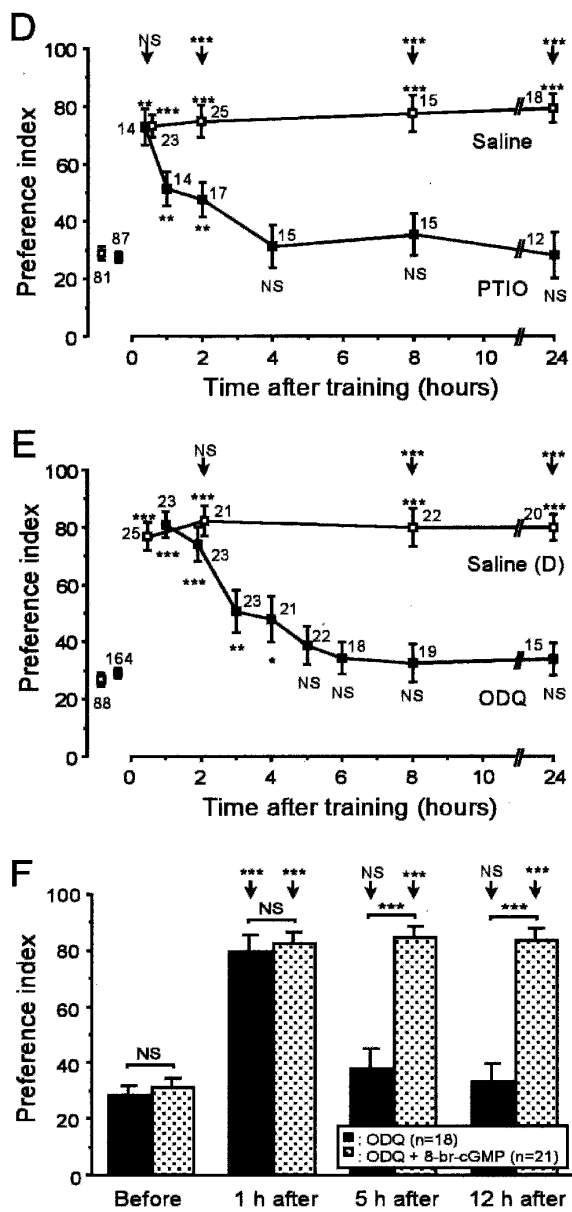

Figure 2. Effects of inhibitors of components of the NO-cGMP pathway on LTM formation. At 20 min prior to multiple-trial conditioning, animals were each injected with $3 \mu \mathrm{L}$ of saline or saline containing various drugs. The preference indexes (PIs) before and at $8 \mathrm{~h}(B)$ or at various times after conditioning $(A, C-F)$ are shown as means \pm SE. In $A$, animals in 10 experimental groups were each injected with L-NAME $(400 \mu \mathrm{M})(\mathbf{\square})$ and animals in another four control groups were each injected with D-NAME $(400 \mu \mathrm{M})(\square)$. In $B$, animals in five groups were each injected with $0.1-400 \mu \mathrm{M} \mathrm{L-NAME}$, and animals in a control group were each injected with saline. In $C$, animals in one group were each injected with L-NAME $(400 \mu \mathrm{M})$ and SNAP $(200 \mu \mathrm{M})$ (shaded bars) and animals in another group were each injected with L-NAME $(400 \mu \mathrm{M})$ and degassed SNAP $(200 \mu \mathrm{M})$ (black bars). Odor preferences of these animals were tested before and at 1,5 , and $12 \mathrm{~h}$ after conditioning. In $D$, animals in six groups were each injected with PTIO $(10 \mu \mathrm{M})$ (black squares) and animals in another four control groups were injected with saline (open squares). In $E$, animals in eight groups were each injected with ODQ (200 $\mu \mathrm{M})$ dissolved in saline containing $0.1 \%$ DMSO ( $\square$ ), and animals in another four control groups were each injected with saline containing $0.1 \%$ DMSO (saline $(D)$ group, $\square$ ). In $F$, animals in one group were each injected with ODQ $(200 \mu \mathrm{M})$ and 8-br-cGMP $(200 \mu \mathrm{M})$ (shaded bars) and animals in another one group were each injected with ODQ $(200 \mu \mathrm{M})$ (black bars). Odor preference tests were done on animals in these groups before and at 1, 5, and 12 hours after conditioning. In $A, B, D$, and $E$, the Pls before conditioning are shown as pooled data from all experimental or control groups. Odor preferences were compared before and after conditioning for each group (WCX test) and between experimental and control groups at each time after conditioning (M-W test), and the results are shown at each data point and above the arrow, respectively. $\left(^{*}\right) P<0.05 ;\left({ }^{* *}\right) P<0.01 ;\left({ }^{* *}\right) P<0.001$; (NS) $P>0.05$. The number of animals tested is shown at each data point. In $A, D$, and $E$, the preferences for rewarded odor remained unchanged from $30 \mathrm{~min}$ to $24 \mathrm{~h}$ after conditioning in the control groups $(P>0.05, \mathrm{M}-\mathrm{W}$ test). The preferences for rewarded odor of the L-NAME+SNAP group $(C)$ and the ODQ+8-br-cGMP group $(F)$ at $12 \mathrm{~h}$ after conditioning did not significantly differ from those of the D-NAME group $(A)$ and the saline $(D)$ group $(E)$ at 8 or $24 \mathrm{~h}$ after conditioning, respectively $(P>0.05$, $\mathrm{M}-\mathrm{W}$ test).

2001) before multiple-trial conditioning. These animals exhibited normal levels of retention at $30 \mathrm{~min}$ after conditioning, but then exhibited a decay of retention with no significant levels of retention at $4 \mathrm{~h}$ after conditioning (Fig. 2D). In contrast, the levels of 24-h retention of control animals injected with saline were not significantly different from those of 30-min retention
(Fig. 2D). Since PTIO cannot permeate the cell membrane, the results suggest that diffusion of NO from neurons to neurons is necessary for LTM formation.

Since the major target of $\mathrm{NO}$ is soluble guanylyl cyclase (Bredt and Snyder 1989), we tested the effect of ODQ (Müller 2000; Aonuma and Newland 2001, 2002), an inhibitor of soluble guanylyl cyclase, on memory retention. At $1 \mathrm{~h}$ after multiple-trial conditioning, animals injected with ODQ $(200 \mu \mathrm{M})$ exhibited normal levels of retention, but then exhibited a decay of retention with no significant levels of retention at $5 \mathrm{~h}$ after conditioning (Fig. 2E). In this experiment, ODQ was dissolved in saline containing 0.1\% DMSO, and the levels of 24-h retention of control animals injected with saline containing $0.1 \%$ DMSO were not significantly different from those of 30-min retention (Fig. 2E). Memory impairment by ODQ was fully rescued by coinjection of a membranepermeable cGMP analog, 8-br-cGMP (200 $\mu \mathrm{M})$ (Fig. 2F). The results suggest that cGMP production is necessary for LTM formation.

One of the major targets of cGMP is a cGMP-dependent protein kinase, PKG (Garthwaite and Boulton 1995). We studied the effect of KT5823 (Maniere et al. 2003), a PKG inhibitor, on memory retention. At $24 \mathrm{~h}$ after multiple-trial conditioning, the levels of retention of animals injected with KT5823 (1 mM) did not significantly differ from those of control animals injected with saline containing 0.1\% DMSO (Fig. 3A). Thus, no evidence suggesting that PKG participates in LTM formation was obtained.

We then investigated whether inhibitors of the cAMP pathway affect the formation of LTM. Animals injected with $200 \mu \mathrm{M}$ KT5720 (Müller 2000), a cAMP-dependent protein kinase (PKA) inhibitor, exhibited normal levels of retention at 30 min after conditioning, but then they exhibited a decay of retention with no significant levels of retention at $3 \mathrm{~h}$ after conditioning (Fig. 3A). Animals injected with $1 \mathrm{mM}$ DDA (Wenzel et al. 2002; Bhattacharya et al. 2004)

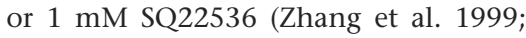
Heinrich et al. 2001), an adenylyl cyclase inhibitor, also exhibited normal retention at $30 \mathrm{~min}$, but exhibited a complete decay of memory at $3 \mathrm{~h}$ after conditioning (Fig. 3B). The results suggest that the production of cAMP and the activation of PKA are necessary for LTM formation.

Induction of LTM by activation of the NO-cGMP or cAMP pathway

To test whether activators of the NO-cGMP pathway or the cAMP-PKA pathway can facilitate LTM formation, animals in 
A
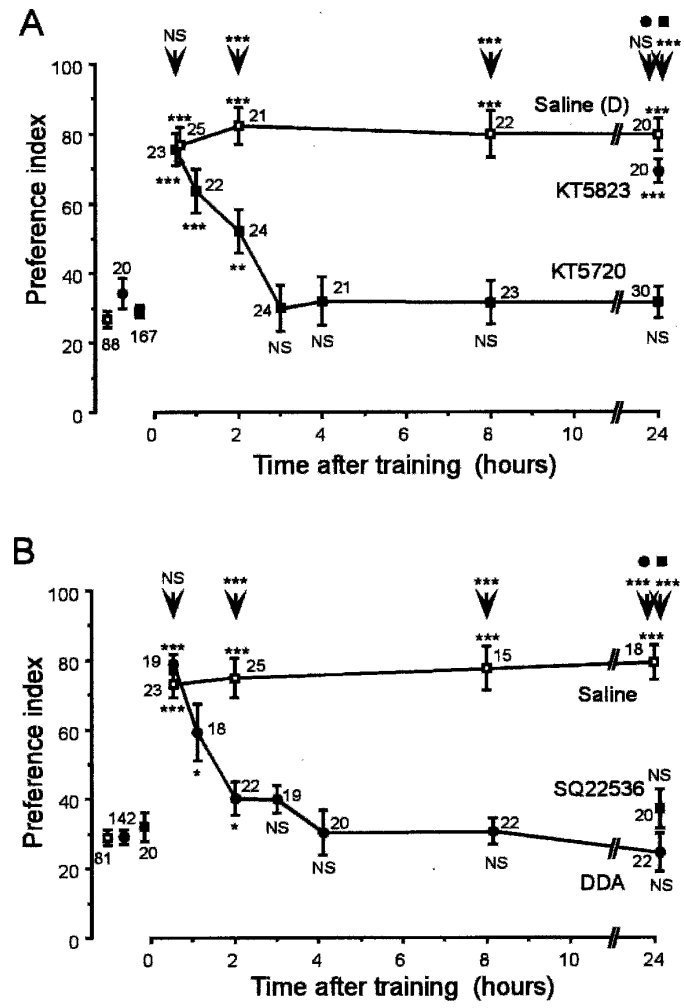

Figure 3. Effects of the PKG inhibitor KT5823, the PKA inhibitor KT5720, and the adenylyl cyclase inhibitor DDA or SQ22536 on LTM formation. At 20 min prior to multiple-trial conditioning, animals were injected with $3 \mu \mathrm{L}$ of saline containing drugs. In $A$, animals in seven groups were each injected with KT5720 $(200 \mu \mathrm{M})(\boldsymbol{\square})$ and animals in another group were each injected with KT5823 (1 mM) $(\bullet)$. These drugs were dissolved in saline containing $0.1 \% \mathrm{DMSO}$, and animals in another four control groups were each injected with saline containing $0.1 \%$ DMSO ( $\square$ ). In $B$, animals in seven groups were each injected with DDA (1 $\mathrm{mM})(\bullet)$, animals in one group were injected with SQ22536 (1 mM) (घ) and animals in another four groups were each injected with saline ( $\square$ ). Odor preferences tests were done before and at various times after conditioning. Preference indexes (PIs) are shown as means \pm SE. The Pls before conditioning for KT5720, DDA, and saline-injected groups are shown as pooled data from all groups. Odor preferences were compared before and after conditioning (WCX test) and between experimental and control groups (M-W test), and the results are shown at each data point and above the arrow, respectively. $\left(^{*}\right) P<0.05$; $\left(^{* *}\right) P<0.01 ;\left({ }^{* * *}\right)$ $P<0.001$; (NS) $P>0.05$, WCX-test. The number of animals tested is shown at each data point.

four groups were each injected with $200 \mu \mathrm{M}$ SNAP (an NO donor), $200 \mu \mathrm{M}$ 8-br-cGMP (a membrane-permeable cGMP analogue), $200 \mu \mathrm{M}$ forskolin (an adenylyl cyclase activator), or 200 $\mu \mathrm{M}$ DB-cAMP (a cAMP analog) at $20 \mathrm{~min}$ prior to single-trial conditioning. Remarkably, all four groups exhibited significant levels of retention at $24 \mathrm{~h}$ after conditioning (Fig. 4), which were as high as those in saline-injected animals at $24 \mathrm{~h}$ after multipletrial conditioning shown in Figure 2D. Animals in the control group were injected with $200 \mu \mathrm{M}$ SNAP and received no conditioning trial. These animals exhibited no significant change of odor preference at $24 \mathrm{~h}$ after injection compared with that before injection (data not shown). We also tested the effect of IBMX, an inhibitor of phosphodiesterases, which degrades both cGMP and cAMP. Animals injected with $200 \mu \mathrm{M}$ IBMX, dissolved in saline containing 0.1\% DMSO, before single-trial conditioning exhibited significant levels of retention at $24 \mathrm{~h}$ after conditioning (Fig. 4 ), and these levels were as high as those of control animals injected with saline containing 0.1\% DMSO at $24 \mathrm{~h}$ after multiple-trial conditioning (shown in Fig. 2E). The results suggest that an externally applied activator of the NO-cGMP pathway or cAMP-PKA pathway can trigger a biochemical cascade leading to LTM formation when paired with single-trial conditioning. This is comparable to the finding in honey bees that local uncaging of cGMP (but not NO) in the antennal lobe (primary olfactory center) paired with single-trial conditioning led to olfactory LTM (Müller 2000). The biochemical cascade leading to LTM formation was then examined by testing the effects of various combinations of drugs for "gain of function" (NO donor, cGMP analog, forskolin, cAMP analog) and those for "loss of function" (LNAME, ODQ, DDA, KT5720). LTM was routinely monitored at 24 $\mathrm{h}$ after conditioning.

\section{Induction of LTM by an NO donor, cGMP analog, or cAMP analog is mediated by PKA and protein synthesis}

An experiment was carried out to determine whether induction of LTM by an NO donor, cGMP analog, or cAMP analog paired with single-trial conditioning is mediated by protein synthesis, as is LTM induced by multiple-trial conditioning (Matsumoto et al. 2003). Animals in three groups were each coinjected with a protein synthesis inhibitor, cycloheximide $(10 \mathrm{mM})$, and either SNAP $(200 \mu \mathrm{M}), 8$-br-cGMP $(200 \mu \mathrm{M})$, or DB-cAMP $(200 \mu \mathrm{M})$, and then the animals were subjected to single-trial conditioning. None of the animals exhibited significant levels of retention at $24 \mathrm{~h}$ after conditioning (Fig. 5A), thus suggesting that induction of LTM by either NO, a cGMP analog, or cAMP analog paired with single-trial conditioning is mediated by protein synthesis.

Next, an experiment was carried out to determine whether induction of LTM by either SNAP, 8-br-cGMP, or DB-cAMP paired with single-trial conditioning is mediated by PKA, as is LTM induced by multiple-trial conditioning (Fig. 3B). Induction of LTM by SNAP $(200 \mu \mathrm{M})$, 8-br-cGMP $(200 \mu \mathrm{M})$, or DB-cAMP $(200 \mu \mathrm{M})$ paired with single-trial conditioning was completely inhibited by coinjection of a PKA inhibitor, KT5720 (200 $\mu \mathrm{M})($ Fig. 5A), thus suggesting that induction of LTM by an NO donor, cGMP analog, or cAMP analog is mediated by PKA.

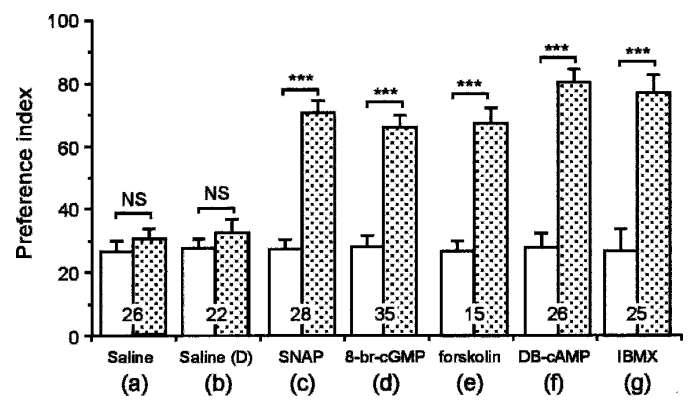

Figure 4. Effects of SNAP, 8-br-cGMP, forskolin, DB-cAMP, and IBMX on LTM formation. At 20 min prior to single-trial conditioning, animals in two groups were each injected with $3 \mu \mathrm{L}$ of saline (a) or saline containing $0.1 \%$ DMSO (b), and animals in another five groups were each injected with $3 \mu \mathrm{L}$ of saline containing SNAP $(200 \mu \mathrm{M})(\mathrm{c}), 8$-br-cGMP $(200 \mu \mathrm{M})$ (d), forskolin $(200 \mu M)(e)$, DB-CAMP $(200 \mu M)(f)$, or IBMX $(200 \mu M)$ and $0.1 \% \mathrm{DMSO}(\mathrm{g})$. The Pls were measured before conditioning (white bars) and $24 \mathrm{~h}$ after conditioning (shaded bars) and are shown as means \pm SE., and the results of statistical comparison between them are indicated. $\left.{ }^{* * *}\right) P<0.001$, (NS) $P>0.05$, WCX test. The number of animals tested is shown at each data point. The odor preferences at $24 \mathrm{~h}$ after conditioning of the groups shown in $\mathrm{c}-\mathrm{g}$ did not significantly differ among each other $(P>0.05$, K-W test).

\section{Learning \& Memory}


A

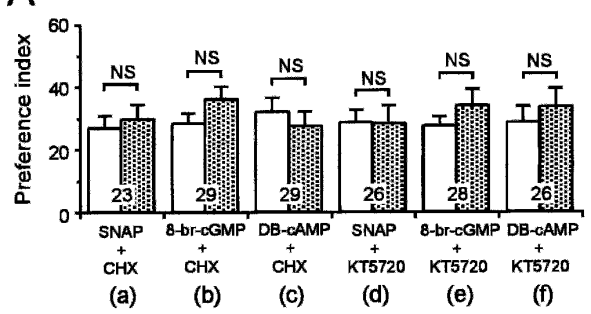

B

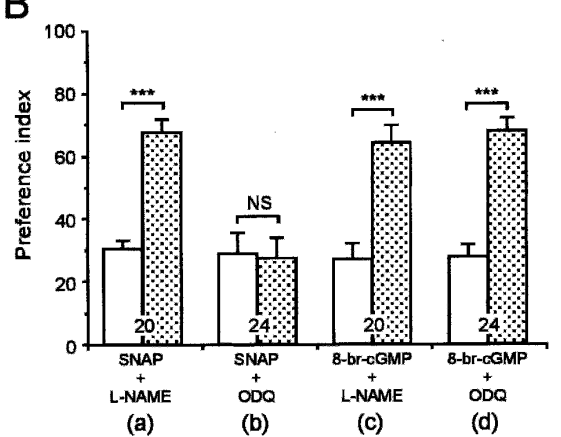

C

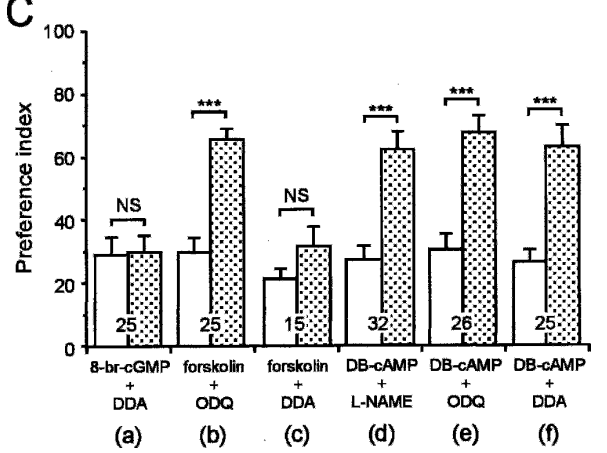

Figure 5. Effects of various drugs on induction of LTM by an NO donor, CGMP analog, forskolin, or CAMP analog paired with single-trial conditioning. At 20 min prior to single-trial conditioning, animals were injected with $3 \mu \mathrm{L}$ of saline containing various drugs. In $A$, animals in six groups were each coinjected with SNAP $(200 \mu \mathrm{M})$ and cycloheximide (CHX, 10 $\mathrm{mM})(\mathrm{a}), 8$-br-cGMP $(200 \mu \mathrm{M})$ and CHX $(10 \mathrm{mM})(\mathrm{b})$, DB-CAMP $(200$ $\mu \mathrm{M})$ and $\mathrm{CHX}(10 \mathrm{mM})(\mathrm{c})$, SNAP $(200 \mu \mathrm{M})$ and KT5720 $(200 \mu \mathrm{M})(\mathrm{d})$, 8-br-cGMP $(200 \mu \mathrm{M})$ and KT5720 $(200 \mu \mathrm{M})(\mathrm{e})$, or DB-CAMP $(200 \mu \mathrm{M})$ and KT5720 $(200 \mu \mathrm{M})(\mathrm{f})$. In $B$, animals in four groups were each coinjected with SNAP $(200 \mu \mathrm{M})$ and L-NAME $(400 \mu \mathrm{M})(\mathrm{a})$, SNAP $(200 \mu \mathrm{M})$ and ODQ $(200 \mu \mathrm{M})(\mathrm{b}), 8$-br-cGMP $(200 \mu \mathrm{M})$ and L-NAME $(400 \mu \mathrm{M})(\mathrm{c})$, or 8-br-cGMP $(200 \mu \mathrm{M})$ and ODQ $(200 \mu \mathrm{M})(\mathrm{d})$. In C, animals in six groups were each coinjected with 8-br-cGMP $(200 \mu \mathrm{M})$ and DDA $(1 \mathrm{mM})$ (a), forskolin $(200 \mu \mathrm{M})$ and ODQ $(200 \mu \mathrm{M})(\mathrm{b})$, forskolin $(200 \mu \mathrm{M})$ and DDA $(1 \mathrm{mM})(\mathrm{c}), \mathrm{DB}-\mathrm{CAMP}(200 \mu \mathrm{M})$ and L-NAME $(400 \mu \mathrm{M})(\mathrm{d})$, DBCAMP $(200 \mu \mathrm{M})$ and ODQ $(200 \mu \mathrm{M})(\mathrm{e})$, or DB-CAMP $(200 \mu \mathrm{M})$ and DDA $(1 \mathrm{mM})(\mathrm{f})$. The Pls measured before (white bars) and $24 \mathrm{~h}$ after conditioning (shaded bars) are shown as means \pm SE. The results of statistical comparison before and $24 \mathrm{~h}$ after conditioning are shown. $\left.{ }^{* * *}\right)$ $P<0.001$, (NS) $P>0.05$, WCX test. The number of animals tested is shown at each data point. The odor preferences at $24 \mathrm{~h}$ after conditioning of the groups shown in $a, c$, and $d$ in $B$ and $b, d$, e, and $f$ in $C$ did not significantly differ among each other $(P>0.5, \mathrm{~K}-\mathrm{W}$ test).

\section{Relationship between the NO-cGMP pathway} and CAMP pathway for the induction of LTM

Although the typical target of NO is soluble guanylyl cyclase, NO may act on some other targets (Bicker 2001). Thus, an experiment was carried out to determine whether induction of LTM by an NO donor paired with single-trial conditioning is indeed me- diated by cGMP. Induction of LTM by SNAP $(200 \mu \mathrm{M})$ paired with single-trial conditioning was not affected by coinjection of the NO synthase inhibitor L-NAME $(400 \mu \mathrm{M})$, but was blocked by coinjection of the soluble guanylyl cyclase inhibitor ODQ (200 $\mu \mathrm{M})$. In contrast, induction of LTM by 8-br-cGMP $(200 \mu \mathrm{M})$ was unaffected by coinjection of either L-NAME $(400 \mu \mathrm{M})$ or ODQ $(200 \mu \mathrm{M})$. (Fig. 5B). The results suggest that induction of LTM by NO is mediated by cGMP and not vice versa.

In honey bees, local uncaging of cGMP in the antennal lobe led to activation of PKA (Müller 2000), and a biochemical study has suggested that PKA can be activated by either cAMP or cGMP (Leboulle and Müller 2004). Thus, we asked whether direct activation of PKA by cAMP or CGMP underlies the formation of LTM. Induction of LTM by DB-cAMP $(200 \mu \mathrm{M})$ paired with single-trial conditioning was unaffected by L-NAME $(400 \mu \mathrm{M})$, ODQ $(200$ $\mu \mathrm{M})$, or DDA $(1 \mathrm{mM})$. In contrast, induction of LTM by 8 -brcGMP $(200 \mu \mathrm{M})$ paired with single-trial conditioning was blocked by the adenylyl cyclase inhibitor DDA (1 mM) (Fig. 5C). Similarly, induction of LTM by the adenylyl cyclase activator forskolin $(200 \mu \mathrm{M})$ paired with single-trial conditioning was unaffected by ODQ $(200 \mu \mathrm{M})$ and was blocked by DDA $(1 \mathrm{mM})$. The results suggest that the induction of LTM by the NO-cGMP pathway is mediated via the adenylyl cyclase-cAMP pathway and not vice versa, hence ruling out the possibility that cGMP directly activates PKA.

Cyclic nucleotide-gated anion channel and calmodulin intervene between the NO-cGMP pathway and cAMP pathway

Next, biochemical pathways intervening between cGMP production and adenylyl cyclase activation were investigated. One of the possible targets of cGMP is PKG, but the PKG inhibitor KT5823 (1 mM) did not impair LTM formed by multiple-trial conditioning (Fig. 3A) or that induced by 8 br-cGMP $(200 \mu \mathrm{M})$ paired with single-trial conditioning (Fig. 6A). We therefore tested another possibility, namely, that the cyclic nucleotidegated anion channel (CNG channel) participates in LTM formation. We tested two kinds of CNG channel inhibitors, $l$-cis diltiazem (L-DIL) and 3, 4, -dechlorobenzamil (DCB); the former has been used in many animals (Nagy 1994 in Limulus; Gotow et al. 1997 in mollusks) including insects (Murata et al. 2006), and the latter has been used in mollusks (Gomez and Nasi 1997). Injection of L-DIL $(1 \mathrm{mM})$ or DCB $(1 \mathrm{mM})$ before multiple-trial conditioning completely impaired 24 -h retention, while 30-min retention was normal (Fig. 6B), suggesting that the CNG channel participates in LTM formation. Moreover, induction of LTM by 8-br-cGMP $(200 \mu \mathrm{M})$ paired with single-trial conditioning was impaired by L-DIL $(1 \mathrm{mM})$ or DCB $(1 \mathrm{mM})$, while induction of LTM by forskolin $(200 \mu \mathrm{M})$ paired with single-trial conditioning was unaffected by L-DIL $(1 \mathrm{mM})$ or DCB $(1 \mathrm{mM})$, and that by DB-cAMP $(200 \mu \mathrm{M})$ paired with single-trial conditioning was unaffected by L-DIL $(1 \mathrm{mM})$ (Fig. $6 \mathrm{~A})$. The results suggest that the $\mathrm{CNG}$ channel intervenes between cGMP production and adenylyl cyclase activation for the formation of LTM.

The L-DIL used in this study is $98 \%$ in purity and contains a very small amount of D-DIL, which is an isomer of L-DIL and is known to inhibit L-type voltage-sensitive calcium channel in insects (Hsieh et al. 2002). Therefore, we tested the effects of verapamil (Hsieh et al. 2002), an inhibitor of L-type calcium channel. Injection of verapamil ( $1 \mathrm{mM})$ before multiple-trial conditioning had no effects on 24-h retention (data not shown), thereby suggesting that the observed impairment of LTM by LDIL is not due to inhibition of L-type calcium channels.

Biochemical study of adenylyl cyclase in Drosophila has shown that it is activated by either calcium-calmodulin stimula- 
A

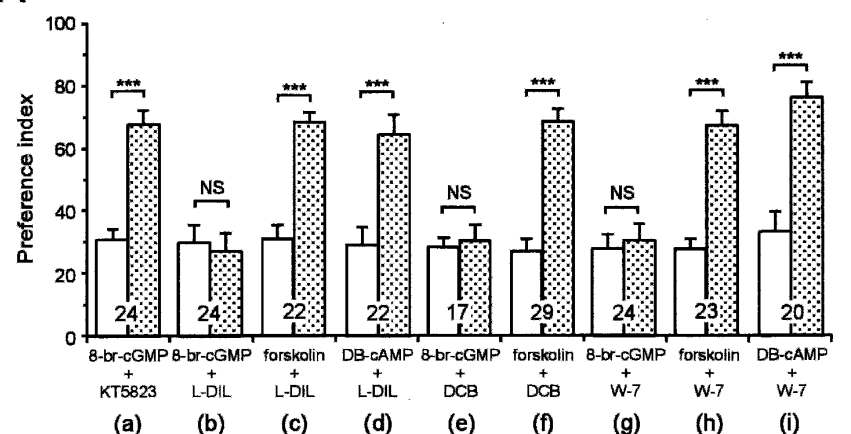

B

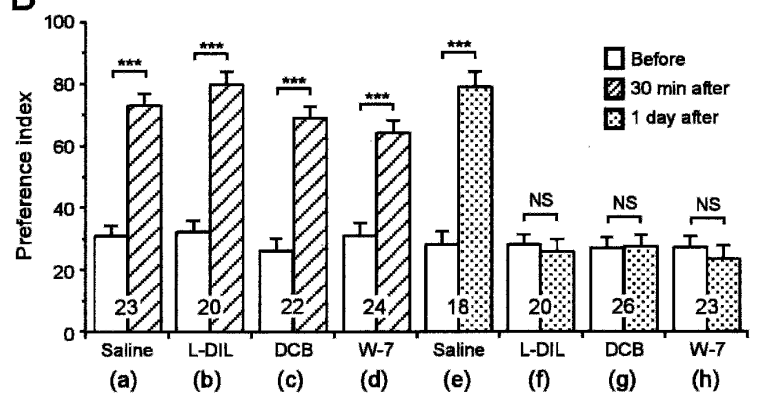

C

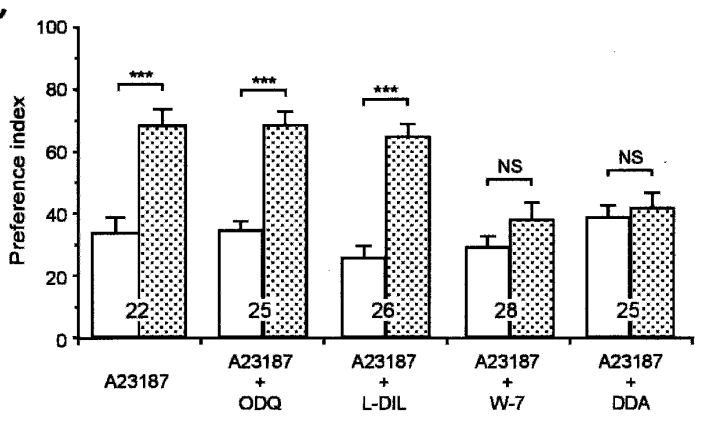

(a)

(b)

(c)

(d)

(e)

Figure 6. Investigation of the biochemical pathway intervening the NO-cGMP pathway and adenylyl cyclase-cAMP-PKA pathway. In A, animals in nine groups were each coinjected with $3 \mu \mathrm{L}$ of saline containing 8-br-cGMP $(200 \mu \mathrm{M})$ and KT5823 $(200 \mu \mathrm{M})(\mathrm{a})$, 8-br-cGMP $(200 \mu \mathrm{M})$ and L-DIL ( $1 \mathrm{mM})(\mathrm{b})$, forskolin $(200 \mu \mathrm{M})$ and L-DIL (1 mM) (c), DB-CAMP $(200 \mu \mathrm{M})$ and L-DIL $(1 \mathrm{mM})(\mathrm{d}), 8$-br-cGMP $(200 \mu \mathrm{M})$ and DCB $(1 \mathrm{mM})$ (e), forskolin $(200 \mu \mathrm{M})$ and DCB $(1 \mathrm{mM})(\mathrm{f}), 8$-br-cGMP $(200 \mu \mathrm{M})$ and W-7 $(200 \mu \mathrm{M})(\mathrm{g})$, forskolin $(200 \mu \mathrm{M})$ and W-7 $(200 \mu \mathrm{M})(\mathrm{h})$, or DB-CAMP $(200 \mu \mathrm{M})$ and $\mathrm{W}-7(200 \mu \mathrm{M})$ (i) before single-trial conditioning. The Pls before (white bars) and at $24 \mathrm{~h}$ after conditioning (shaded bars) are shown as means $\pm \mathrm{SE}$. In $B$, animals in two groups were each injected with $3 \mu \mathrm{L}$ saline $(\mathrm{a}, \mathrm{e})$ and animals in another six groups were each injected with $3 \mu \mathrm{L}$ saline containing L-DIL $(1 \mathrm{mM})(b, f), D C B(1 \mathrm{mM})(c, g)$, or W-7 $(200 \mu \mathrm{M})(\mathrm{d}, \mathrm{h})$ before multiple-trial conditioning. Pls were measured before (white bars) and at 30 min (hatched bars) or $1 \mathrm{~d}$ (shaded bars) after conditioning and are shown as mean \pm SE. In C, animals in five groups were each injected with $3 \mu \mathrm{L}$ saline containing A23187 $(200 \mu \mathrm{M})$ (a), A23187 $(200 \mu \mathrm{M})$ and ODQ $(200 \mu \mathrm{M})(\mathrm{b}), \mathrm{A} 23187(200 \mu \mathrm{M})$ and L-DIL $(1 \mathrm{mM})(\mathrm{c}), \mathrm{A} 23187(200 \mu \mathrm{M})$ and W7 $(200 \mu \mathrm{M})(\mathrm{d})$, or A23187 $(200 \mu \mathrm{M})$ and DDA $(1 \mathrm{mM})(\mathrm{e})$. The Pls measured before (white bars) and $24 \mathrm{~h}$ (shaded bars) after conditioning are shown as means \pm SE. The results of statistical comparison before and $24 \mathrm{~h}$ after conditioning are shown. ( $\left.{ }^{* * *}\right) P<0.001$, (NS) $P>0.05$, WCX test. The number of animals tested is shown at each data point. The odor preferences at $24 \mathrm{~h}$ after conditioning of the groups shown in a, c, d, f, h, and $i$ in $A$ and $a, b, c$ in $C$ did not significantly differ among each other $(P>0.05, \mathrm{~K}-\mathrm{W}$ test).

tion or G-protein stimulation (Livingstone et al. 1984). We investigated the possibility that calmodulin intervenes between CNG channel activation and adenylyl cyclase activation. Animals injected with $200 \mu \mathrm{M} \mathrm{W-7} \mathrm{(Matsumoto} \mathrm{et} \mathrm{al.} \mathrm{1995),} \mathrm{a}$ calmodulin antagonist, before multiple-trial conditioning exhibited complete impairment of 24-h retention (Fig. 6B), while 30min retention was normal. Moreover, W-7 (200 $\mu \mathrm{M})$ impaired induction of LTM by 8-br-cGMP $(200 \mu \mathrm{M})$ paired with single-trial conditioning, while induction of LTM by forskolin $(200 \mu \mathrm{M})$ or DB-cAMP $(200 \mu \mathrm{M})$ paired with single-trial conditioning was unaffected by W-7 $(200 \mu \mathrm{M})$ (Fig. 6A). These results suggest that calmodulin intervenes between cGMP production and adenylyl cyclase activation in the biochemical pathway for the induction of LTM.

Next, we investigated the possibility that an increase of calcium concentration intervenes between CNG channel activation and calmodulin activation. Animals injected with $200 \mu \mathrm{M}$ A23187 (Rybczynki and Gilbert 2003), a calcium ionophore, before single-trial conditioning exhibited a significant level of retention at $24 \mathrm{~h}$ after conditioning (Fig. 6C). Induction of LTM by injection of A23187 $(200 \mu \mathrm{M})$ paired with single-trial conditioning was unaffected by coinjection of ODQ $(200 \mu \mathrm{M})$ or L-DIL $(1$ $\mathrm{mM})$, but was fully impaired by coinjection of W-7 $(200 \mu \mathrm{M})$ or DDA (1 mM) (Fig. 6C). The results suggest that calcium intervenes between CNG channel activation and calmodulin activation, thus completing the signaling cascade for LTM formation. The results of this study are summarized in Table 1 to facilitate further discussion.

\section{Discussion}

A common feature of memory formation in vertebrates and invertebrates is that the cAMP-PKA-CREB pathway plays an essential role in induction of LTM (DeZazzo and Tully 1995; Kandel 2001). Our behavioral and pharmacological study provides the first evidence that the NO-cGMP pathway stimulates the cAMP pathway to induce LTM, thereby demonstrating a new role for the NO-cGMP pathway in LTM formation. Moreover, our study suggests that the $\mathrm{CNG}$ channel and the calcium-calmodulin pathway intervene between the NO-cGMP pathway and cAMPPKA pathway. Previous studies on the roles of the NO-cGMP pathway in long-term neural plasticity in the rat hippocampus (Lu et al. 1999; Lu and Hawkins 2002) and in nociceptive sensory receptors in Aplysia (Lewin and Walters 1999) suggested that the NO-cGMP pathway acts in parallel with the cAMP-PKA pathway to activate CREB, via PKG, for the formation of long-term neural plasticity. The NO-cGMP pathway plays an essential role in many systems of long-term neural and behavioral plasticity (Kendrick et al. 1997; Hawkins et al. 1998; Wong et al. 1999; Katzoff et al. 2002; Kemenes et al. 2002; Lev-Ram et al. 2002). It would be interesting to determine the extent by which our finding that the NO-cGMP pathway triggers LTM formation by stimulating the cAMP pathway is applicable to other systems.

A model of the biochemical pathway for the formation of LTM in associative olfactory learning is presented in Figure 7. This is the most parsimonious (shortest) signaling pathways to account for the effects of various combinations of "LTMinducing" drugs and "LTM-inhibiting" ones summarized in Table 1, and incorporates the following documented findings in the fruitfly Drosophila: (1) NO production by NO synthase is stimulated by calcium-calmodulin (Regulski and Tully 1995), (2) adenylyl cyclase can be stimulated by either calcium-calmodulin or the G-protein coupled receptor (Livingstone et al. 1984), and (3) PKA activates CREB to induce LTM (Yin et al. 1995).

When evaluating the proposed model, it should be cautioned that one potential difficulty of behavioral pharmacology 
Table 1. Summary of effects of inhibitors on 30-min and 24-h retention

\begin{tabular}{|c|c|c|c|c|c|c|c|}
\hline Inhibitor & L-NAME & ODQ & L-DIL & W-7 & DDA & KT5720 & $\mathrm{CHX}$ \\
\hline Target & NOS & sGC & $\begin{array}{l}\text { CNG } \\
\text { channel }\end{array}$ & CAM & $\mathrm{AC}$ & PKA & $\begin{array}{l}\text { Protein } \\
\text { synthesis }\end{array}$ \\
\hline Effects on 30-min retention & no & no & no & no & no & no & (no \\
\hline after 4 trial conditioning & effects & effects & effects & effects & effects & effects & effects) $^{1}$ \\
\hline \multicolumn{8}{|c|}{ Effects on 24-hr retention after: } \\
\hline 4 trial & fully & fully & fully & fully & fully & fully & (fully \\
\hline conditioning & impaired & impaired & impaired & impaired & impaired & impaired & ${\text { impaired })^{1}}$ \\
\hline $\mathrm{SNAP}+1$ trial & no & fully & - & - & - & fully & fully \\
\hline conditioning & effects & impaired & & & & impaired & impaired \\
\hline $8 \mathrm{br}-\mathrm{cGMP}+1$ trial & no & no & fully & fully & fully & fully & fully \\
\hline conditioning & effects & effects & impaired & impaired & impaired & impaired & impaired \\
\hline A23187+ 1 trial & - & no & no & fully & fully & - & - \\
\hline conditioning & & effects & effects & impaired & impaired & & \\
\hline forskolin +1 trial & - & no & no & no & fully & - & - \\
\hline conditioning & & effects & effects & effects & impaired & & \\
\hline DB-cAMP+ 1 trial & no & no & no & no & no & fully & fully \\
\hline conditioning & effects & effects & effects & effects & effects & impaired & impaired \\
\hline
\end{tabular}

\footnotetext{
${ }^{1}$ Matsumoto et al. (2003); (NOS) NO synthase; (SGC) soluble guanylyl cyclase; (CNG channel) cyclic nucleotide-gated anion channel; (CAM) calmodulin; (AC) adenylyl cyclase; (PKA) protein kinase A; (L-DIL) 1-cis-diltiazem; (DDA) 2'5'dideoxyadenosine; $(\mathrm{CHX})$ cycloheximide.
}

is that drugs may act on various neurons in various brain regions, as well as on non-neuronal cells, and thus may lead to complicated effects on behavior. Therefore, it was rather exceptional that all drugs used in this study specifically facilitated or inhibited induction of LTM without affecting retention at 30 min after conditioning, which suggests that the drugs specifically affected LTM formation. This obviously reflects the relative simplicity of the nervous system of crickets.

Although efficacy of all inhibitors used in this study, except for DCB, has been reported in biochemical or physiological studies in insects (see references cited in the Results section), it should be cautioned that the specificity of inhibitors may not necessarily be perfect and they may have affected on enzymes other than their targets. We observed, however, no complicated effects of inhibitors in studies with systematic coinjection of various "LTM-inducing" and "LTM-blocking" drugs (Table 1) and thus, it seems less likely that the proposed model is biased by unspecific side effects of inhibitors. Considering that behavioral pharmacological study has limitations as well as effectiveness, future complementary biochemical and electrophysiological studies are required to confirm the validity of the proposed model.

We found no evidence of signaling pathways acting in parallel with the proposed NO-cGMP, calcium-calmodulin, and cAMP-PKA cascade, since injection of inhibitors of any enzymes of the proposed cascade resulted in a complete impairment of LTM formation, not a partial impairment that would be expected if there are parallel signaling pathways supplementing the proposed pathway.

Some questions need to be solved for confirming the model depicted in Figure 7. First, the possible involvement of PKG is not yet fully ruled out, since we tested only one inhibitor. If PKG is involved in the signaling cascade, it should be upstream of the 


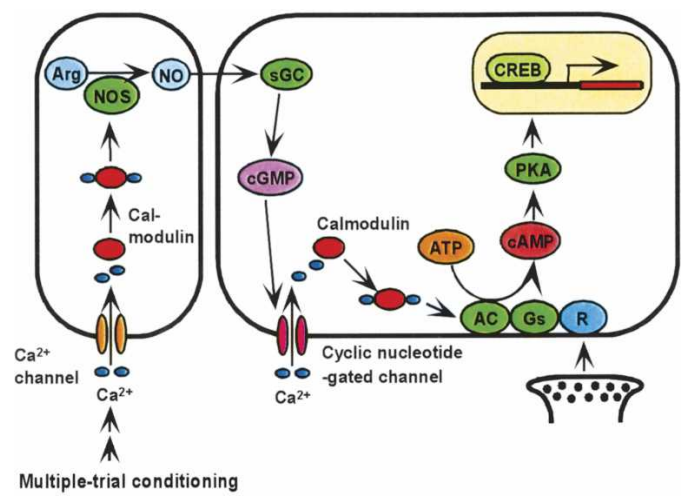

Figure 7. A model of biochemical pathways for LTM formation in associative olfactory conditioning. The model is proposed on the basis of the present findings in crickets and some documented findings in fruitflies (see text). Multiple-trial conditioning activates the NO-cGMP pathway, and this in turn activates the adenylyl cyclase (AC)-CAMP-PKA-CREB (cAMP-responsive element-binding protein) signaling pathway via the CNG channel and calcium-calmodulin, resulting in protein synthesisdependent LTM formation. (CAM) Calmodulin; (Arg) arginine; (Gs) receptor; (R)-coupled G-protein.

CNG channel, because induction of LTM by injection of 8-brcGMP, which activates PKG, paired with single-trial conditioning was completely inhibited by coinjection of L-DIL or DCB. Second, it remains to be determined whether or not the production of cGMP and cAMP occurs in the same compartment of the same neurons; the present pharmacological study provides no information about the localization of components of the signaling pathway within the brain. Third, although it has been reported that insect CNG channel is 50 times less sensitive to cAMP compared with cGMP (Baumann et al. 1994), the possibility that CNG channels are partially activated by cAMP, thus forming a positive feedback loop for the formation of LTM, remains to be studied. Fourth, it needs to be clarified whether G proteincoupled receptors, which are thought to stimulate adenylyl cyclase (Livingstone et al. 1984), contribute to LTM formation in some experimental conditions.

An unexpected finding is that retention at $30 \mathrm{~min}$ after conditioning was not impaired by inhibitors of adenylyl cyclase, because in Drosophila, rutabaga mutants defective in adenylyl cyclase exhibited a memory decay within a few minutes after conditioning (Dubnau and Tully 1998). Further study is needed to determine whether the time-course of the cAMP-dependent memory phase differs between two species or whether the difference reflects different methods of interference.

A major objective of our ongoing study is determination of neural circuits underlying the LTM formation by anatomically and physiologically studying NO-generating neurons and NOreceptive neurons in the cricket brain. Histochemical studies in honey bees, locusts, and cockroaches have revealed presumable NO synthase activity in some neurons of the antennal lobe (primary olfactory center) and the mushroom body (a higher olfactory and multisensory center) (Müller and Bicker 1994; Bicker 2001; Ott and Elphick 2002), while other neurons in the same centers have been shown to exhibit immunoreactivity to NOinduced cGMP (Bicker et al. 1996; Bicker 2001). In honey bees, prolonged activation of PKA in the antennal lobe is implicated in LTM formation (Müller 2000), while in Drosophila, it is thought that the mushroom body is required for LTM formation (Pascual and Preat 2001). Notably, both the antennal lobe and the mushroom body consist of a number of structural subunits (Müller 1997; Mizunami et al. 1998a,b; Bicker 2001) that have features suitable to act as diffusion compartments (Müller 1997; Bicker
2001). If the NO released within a subunit induces long-term changes in the strength of synaptic connections in a number of target neurons of that particular subunit, the structural subunits may act as functional units for the formation and storage of olfactory LTM. One of our next steps is to identify NO-generating and NO-receptive neurons in the antennal lobe and the mushroom body and to determine whether electrical stimulation or suppression of activities of these neurons during single- or multiple-trial conditioning can facilitate or impair LTM formation.

\section{Materials and Methods}

Adult male crickets, Gryllus bimaculatus, at 1-2 wk after the imaginal molt were used. They were reared in a 12-h light/12-h dark cycle (photophase: 8:00-20:00) at $27 \pm 2^{\circ} \mathrm{C}$ and were fed a diet of insect pellets and water ad libitum. Four days before the start of the experiment, a group of 20-30 animals was placed in a container and fed a diet of insect pellets ad libitum, but deprived of drinking water to enhance their motivation to search for water. On the day of the experiment, they were individually placed in $100-\mathrm{mL}$ glass beakers.

\section{Classical olfactory conditioning}

Classical conditioning procedures used were described elsewhere (Matsumoto and Mizunami 2002a). In short, individual animals received single- or multiple-trial (four-trial) conditioning. In the former, one set of appetitive conditioning trials in which peppermint odor was associated with water reward $(\mathrm{P}+$ conditioning trial) was carried out. In the latter, two sets of P+ conditioning trials and two sets of aversive conditioning trials in which vanilla odor was associated with a solution of $20 \% \mathrm{NaCl}$ (V - conditioning trial) were carried out, in the sequence of $\mathrm{P}+, \mathrm{V}-, \mathrm{P}+$, and $\mathrm{V}-$ conditioning trials with an intertrial interval of $5 \mathrm{~min}$. Hypodermic syringes of $1 \mathrm{~mL}$ each were used for conditioning. A small filter paper was attached to the needle of the syringe. The syringe used for the $\mathrm{P}+$ conditioning trial was filled with water, and the filter paper attached to the needle was soaked with peppermint essence. The syringe used for the $\mathrm{V}$ - conditioning trial was filled with $20 \% \mathrm{NaCl}$ solution, and the filter paper was soaked with vanilla essence. For odor presentation, the filter paper was placed within $1 \mathrm{~cm}$ of the cricket's head. At $2 \mathrm{sec}$ after the onset of odor presentation, a drop of water or saline solution was given to the mouth of the cricket for 2 sec.

\section{Odor preference test}

All groups of animals were subjected to odor preference tests before and at various times after conditioning. The apparatus used for the preference test was as described previously (Matsumoto and Mizunami 2002a). In short, on the floor of the "test chamber" of the apparatus, there were two circular holes that connected the chamber with two of three sources of odor. Each odor source consisted of a cylindrical plastic container containing a filter paper soaked with a $3-\mu \mathrm{L}$ solution of vanilla or peppermint essence covered with a fine gauze net. The three containers were mounted on a rotatable holder. Two odor sources could be located simultaneously just below the holes at the "offer position" by rotating the holder.

Before the preference test, an animal was transferred from the beaker to the "waiting chamber" of the apparatus and left for $4 \mathrm{~min}$ to become accustomed to the surroundings, and then the door to the test chamber was opened. The test started when the animal entered the test chamber. Two minutes later, the relative positions of the vanilla and peppermint sources were changed by rotating the container holder. An odor source was considered to have been visited when the animal probed the top net with its mouth. The time spent for visiting each odor source was measured cumulatively. The preference test lasted for $4 \mathrm{~min}$. If the total time of visits of an animal to either source was less than 10 sec, we considered that the animal was less motivated to visit odor sources, possibly due to a poor physical condition, and the data were rejected. Animals that fell into this category were ca. 
$5 \%$ for the normal or saline-injected group and between $0 \%$ and $9 \%$ for each of the drug-injected groups. At the end of the training, the sliding door was opened and the animal was gently pushed into the waiting chamber, and then the animal was transferred to a beaker. After completing the test session, animals were provided a diet of insect pellets ad libitum.

\section{Pharmacology}

Animals were injected with $3 \mu \mathrm{L}$ of saline containing drugs into the hemolymph of the head using a microsyringe. N $\omega$-nitro-Larginine methyl ester (L-NAME), N $\omega$-nitro-D-arginine methyl ester (D-NAME), S-nitroso-n-acetyl-penicillamine (SNAP), 2phenyl-4,4,5,5-tetramethyl-imidazoline-1-oxyl 3-oxide (PTIO), $1 \mathrm{H}-[1,2,4]$ oxadiazolo-[4,3-a]quinoxalin-1-one (ODQ), 8-bromoguanosine $3^{\prime}: 5^{\prime}$-cyclic monophosphate (8-br-cGMP), $\mathrm{N}^{6}, 2^{\prime}$-Odibutyryladenosine $3^{\prime}: 5^{\prime}$-cyclic monophosphate (dibutyryl cyclic-AMP: DB-cAMP), 3-isobutyl-1-methylxanthine (IBMX), cycloheximide (CHX), 2',5'-dideoxyadenosine (DDA), forskolin, 9-(tetrahydro-2'-furyl) adenine (SQ22536), and dimethyl sulphoxide (DMSO), 3, 4, -dechlorobenzamil hydrochloride (DCB) were purchased from Sigma. KT5720 and KT5823 were purchased from Calbiochem. N-(6-aminohexyl)-5-chloro-1-naphthalenesulfonamide hydrochloride (W-7), (+-)-(E)-4-Ethyl-2[(E)-hydroxyimino]-5-nitro-3- hexenamide (NOR3), and verapamil hydrochloride were purchased from Wako. L-(-)-cis-diltiazem hydrochloride (L-DIL, purity 98\%) and antibiotic A-23187 calcimycin (A-23187) were purchased from Biomol. ODQ, IBMX, NOR3, KT5823, KT5720, W-7, forskolin, verapamil, and A-23187 were dissolved in cricket saline (Matsumoto et al. 2003) containing $0.1 \%$ DMSO, and all other drugs were dissolved in cricket saline. Degassed SNAP was maintained in the dark at room temperature for $24 \mathrm{~h}$ prior to use (Aonuma and Newland 2001).

\section{Data analysis}

Relative odor preference of each animal was measured using the preference index (PI) for rewarded odor (peppermint) (\%), defined as $t_{\mathrm{P}} /\left(t_{\mathrm{P}}+t_{\mathrm{V}}\right) \times 100$, where $t_{\mathrm{P}}$ is the time spent exploring the peppermint source and $t_{V}$ is the time spent exploring the vanilla source. Wilcoxon's (WCX) test was used to compare odor preferences in different tests of a given animal group, the MannWhitney $\mathrm{U}(\mathrm{M}-\mathrm{W})$ test was used to compare odor preferences of different groups and the Kruskal-Wallis (K-W) test was used to compare odor preferences among three or more groups. $P$ values of $<0.05$ were considered statistically significant.

\section{Acknowledgments}

We thank M. Ohara (Fukuoka) for assistance with the language and A. Maruyama for assistance in some experiments. This study was supported by grants from the Japanese Ministry of Promotion of Science to Y.M. and the Ministry of Education, Science, Culture, Sports, and Technology of Japan to M.M. (11168201, 15370031) and H.A. (14704004) and by the Akiyama Foundation to H.A.

\section{References}

Abel, T., Nguyen, P.V., Barad, M., Deuel, T.A.S., and Kandel, E.R. 1997. Genetic demonstration of a role for PKA in the late phase of LTP and in hippocampus-based long-term memory. Cell 88: 615-626.

Aonuma, H. and Newland, P.L. 2001. Opposing actions of nitric oxide on synaptic inputs of identified interneurones in the central nervous system of the crayfish. J. Exp. Biol. 204: 1319-1332.

2002. Synaptic inputs onto spiking local interneurons in crayfish are depressed by nitric oxide. J. Neurobiol. 52: 144-155.

Aonuma, H. and Niwa, K. 2004. Nitric oxide regulates the levels of cGMP accumulation in the cricket brain. Acta Biol. Hung. 55: 65-70.

Bartsch, D., Gjorardo, M., Skehel, P.A., Karl, K.A., Herder, S.P., Chen, M., Bailey, C.H., and Kandel, E.R. 1995. Aplysia CREB2 represses long-term facilitation: Relief of repression converts transient facilitation into long-term functional and structural change. Cell 83: 979-992.

Baumann, A., Frings, S., Godde, M., Seifert, R., and Kraupp, U.B. 1994. Primary structure and functional expression of a Drosophila cyclic nucleotide-gated channel present in eyes and antennae. EMBO J.
13: $5040-5050$.

Bhattacharya, A., Lakhman, SS., and Singh, S. 2004. Modulation of L-type calcium channels in Drosophila pituitary adenylyl cyclase-activating polypeptide (PACAP)-mediated pathway. J. Biol. Chem. 279: 37291-37297.

Bicker, G. 2001. Sources and targets of nitric oxide signaling in insect nervous systems. Cell Tissue Res. 303: 137-146.

Bicker, G., Schmachtenberg, O., and DeVerte, J. 1996. The nitric oxide/cyclic GMP messenger system in olfactory pathway of the locust brain. Eur. J. Neurosci. 8: 2635-2643.

Bredt, D.S. and Snyder, S.H. 1989. Nitric oxide mediates glutamatelinked enhancement of cGMP levels in the cerebellum. Proc. Natl. Acad. Sci. 86: 9030-9033.

DeZazzo, J. and Tully, T. 1995. Dissection of memory formation: From behavioral pharmacology to molecular genetics. Trends Neurosci. 18: $212-218$.

Dubnau, J. and Tully, T. 1998. Gene discovery in Drosophila: New insights for learning and memory. Annu. Rev. Neurosci. 21: 407-444.

Erber, J., Masuhr, T., and Menzel, R. 1980. Localization of short-term memory in the brain of the bee, Apis mellifera. Physiol. Entomol. 5: 343-358.

Garthwaite, J. and Boulton, C.L. 1995. Nitric oxide signaling in the central nervous system. Annu. Rev. Physiol. 57: 683-706.

Garthwaite, J., Charles, S.L., and Chess-Williams, R. 1988. Endothelium-derived relaxing factor release on activation of NMDA receptors suggests a role as intracellular messenger in the brain. Nature 336: 385-388.

Gomez, M.P. and Nasi, E. 1997. Antagonists of the cGMP-gated conductance of vertebrate rods block the photocurrent in scallop ciliary photoreceptors. J. Physiol. 500: 367-378.

Gotow, T., Nishi, T., and Murakami, M. 1997. 4-Aminopyridine and l-cis-diltiazem block the cGMP-activated $\mathrm{K}^{+}$channels closed by light in the molluscan extra-ocular photoreceptors. Brain Res. 745: 303-308.

Hammer, M. and Menzel, R. 1998. Multiple sites of associative odor learning as revealed by local brain microinjections of octopamine in honeybees. Learn. Mem. 5: 146-156.

Hawkins, R.D., Son, H., and Arancio, O. 1998. Nitric oxide as a retrograde messenger during long-term potentiation in hippocampus. Prog. Brain Res. 118: 155-172.

Heinrich, R., Wenzel, B., and Elsner, N. 2001. A role for muscarinic excitation: Control of specific singing behavior by activation of the adenylate cyclase pathway in the brain of grasshoppers. Proc. Natl. Acad. Sci. 98: 9919-9923.

Hsieh, Y.C., Yang, E.C., Hsu, E.L., Chow, Y.S., and Kou, R. 2002. Voltage-dependent calcium channels in the corpora allata of the adult male loreyi leafworm, Mythimna loreyi. Insect Biochem. Mol. Biol. 32: $547-557$.

Kandel, E.R. 2001. The molecular biology of memory storage: A dialogue between genes and synapses. Science 294: 1030-1038.

Katzoff, A., Ben-Gedalya, T., and Susswein, A.J. 2002. Nitric oxide is necessary for multiple memory processes after learning that a food is inedible in Aplysia. J. Neurosci. 22: 9581-9894.

Kemenes, I., Kemenes, G., Andrew, R.J., Benjamin, P.R., and O'Shea, M. 2002. Critical time-window for NO-cGMP dependent long-term memory formation after one-trial appetitive conditioning. $J$. Neurosci. 22: 1414-1425.

Kendrick, K.M., Guevara-Guzman, R., Zorrilla, J., Hinton, M.R., Broad, K.D., Mimmack, M., and Ohkura, S. 1997. Formation of olfactory memories mediated by nitric oxide. Nature 388: 670-674.

Leboulle, G. and Müller, U. 2004. Synergistic activation of insect cAMP-dependent protein kinase A (type II) by cyclicAMP and cyclicGMP. FEBS Lett. 576: 216-220.

Lev-Ram, V., Wong, S.T., Storm, D.R., and Tsien, R.Y. 2002. A new form of cerebellar long-term potentiation is postsynaptic and dependent on nitric oxide but not cAMP. Proc. Nat. Acad. Sci. 99: 8389-8393.

Lewin, M.R. and Walters, E. 1999. Cyclic GMP pathway is critical for inducing long-term sensitization of nociceptive sensory neurons. Nat. Neurosci. 2: 18-23.

Livingstone, M.S., Sziber, P.P., and Quinn, W.G. 1984. Loss of calcium/calmodulin responsiveness in adenylate cyclase of rutabaga, a Drosophila learning mutant. Cell 37: 205-215.

Lu, Y.-F. and Hawkins, R.D. 2002. Ryanodine receptors contribute to cGMP-induced late-phase LTP and CREB phosphorylation in the hippocampus. J. Neurosci. 88: 1270-1278.

Lu, Y.-F., Kandel, E.R., and Hawkins, R.D. 1999. Nitric oxide signaling contributes to late-phase LTP and CREB phosphorylation in the hippocampus. J. Neurosci. 19: 10250-10261.

Maniere, G., Vanhems, E., Gautron, F., and Delbecque, J.-P. 2003. Inhibition of ovarian steroidogenesis by cyclic GMP in a fly. J. Endocrinol. 177: 35-44.

Matsumoto, Y. and Mizunami, M. 2000. Olfactory learning in the 
cricket Gryllus bimaculatus. J. Exp. Biol. 203: 2581-2588.

2002a. Temporal determinants of olfactory long-term retention in the cricket Gryllus bimaculatus. J. Exp. Biol. 205: 1429-1437. 2002b. Lifetime olfactory memory in the cricket Gryllus bimaculatus. J. Comp. Physiol. A 188: 295-299.

. 2004. Context-dependent olfactory learning in an insect. Learn. Mem. 11: 288-293.

Matsumoto, S., Ozawa, R., Uchiumi, K., Kurihara, M., and Mitsui, T. 1995. Intracellular signal transduction of PBAN action in the common cutworm, Spodoptera litura: Effects of pharmacological agents on sex pheromone production in vitro. Insect Biochem. Mol. Biol. 25: 1055-1059.

Matsumoto, Y., Noji, S., and Mizunami, M. 2003. Time course of protein synthesis-dependent phase of olfactory memory in the cricket Gryllus bimaculatus. Zool. Sci. 20: 409-416.

Miyawaki, K., Mito, T., Sarashina, I., Zhang, H., Shinmyo, Y., Ohuchi, H., and Noji, S. 2004. Involvement of Wingless/Armadillo signaling in the posterior sequential segmentation in the cricket, Gryllus bimaculatus (Orthoptera), as revealed by RNAi analysis. Mech. Dev. 121: $119-130$.

Mizunami, M., Iwasaki, M., Okada, R., and Nishikawa, M. 1998a. Topography of modular subunits in the mushroom bodies of the cockroach. J. Comp. Neurol. 399: 153-161.

. 1998b. Topography of four classes of Kenyon cells in the mushroom bodies of the cockroach. J. Comp. Neurol. 399: 162-175.

Montarolo, P.G., Goelet, P., Casterllucci, V.F., Morgan, J., Kandel, E.R., and Schacher, S. 1986. A critical period for macromolecular synthesis in long-term heterosynaptic facilitation in Aplysia. Science 234: $1249-1254$.

Müller, U. 1996. Inhibition of nitric oxide synthase impairs a distinct form of long-term memory in the honeybee, Apis mellifera. Neuron 16: $541-549$.

. 1997. The nitric oxide system in insects. Prog. Neurobiol. 51: $363-381$.

. 2000. Prolonged activation of cAMP-dependent protein kinase during conditioning induces long-term memory in honeybees. Neuron 27: 159-168.

Müller, U. and Bicker, G. 1994. Calcium activated release of nitric oxide and cellular distribution of nitric oxide synthesizing neurons in the nervous system of the locust. J. Neurosci. 14: 7521-7528.

Murata, Y., Ozaki, M., and Nakamura, T. 2006. Inhibitory effects of 1-cis-diltiazem on the response of sugar receptor cells in the blowfly,
Phormia regina. Comp. Biochem. Physiol. A. (in press).

Nagy, K. 1994. Inhibition of the first component of the receptor current in Limulus photoreceptor. NeuroReport 5: 847-849.

Ott, S.R. and Elphick, M.R. 2002. Nitric oxide synthase histochemistry in insect nervous systems: Methanol/formalin fixation reveals the neuroarchitecture of formaldehyde-sensitive NADPH diaphorase in the cockroach Periplaneta americana. J. Comp. Neurol. 448: 165-185.

Pascual, A. and Preat, T. 2001. Localization of long-term memory within the Drosophila mushroom bodies. Science 294: 1115-1117.

Paydar, S., Doan, C.A., and Jacobs, G.A. 1999. Neural mapping of direction and frequency in the cricket cercal sensory system. $J$. Neurosci. 19: 1771-1781.

Regulski, M. and Tully, T. 1995. Molecular and biochemical characterization of dNOS: A Drosophila $\mathrm{Ca}^{2+} /$ calmodulin-dependent nitric oxide synthase. Proc. Natl. Acad. Sci. 92: 9072-9076.

Rybczynki, R. and Gilbert, L.I. 2003. Prothoracicotropic hormone stimulated extracellular signal-regulated kinase (ERK) activity. Mol. Cell Endocrinol. 205: 159-168.

Unoki S., Matsumoto, Y., and Mizunami, M. 2005. Participation of octopaminergic reward system in insect olfactory learning revealed by pharmacological study. Eur. J. Neurosci. 22: 1409-1416.

Wenzel, B., Elsner, N., and Heinrich, R. 2002. mAChRs in the grasshopper brain mediate excitation by activation of the AC/PKA and the PLC second-messenger pathways. J. Neurophysiol. 87: 876-888.

Wong, S.T., Athos, J., Figueroa, X.A., Pineda, V.V., Schaefer, M.L., Chavkin, C.C., Muglia, L.J., and Storm, D.R. 1999. Calcium-stimulated adenylyl cyclase activity is critical for hippocampus-dependent long-term memory and late phase LTP. Neuron 23: 787-798.

Yin, J.C.P., Del Vecchio, M., Zhou, H., and Tully, T. 1995. CREB as a memory modulator: Induced expression of a dCREB2 activator isoform enhances long-term memory in Drosophila. Cell 81: 107-115.

Zhang, D., Kuromi, H., and Kidokoro, Y. 1999. Activation of metabotropic glutamate receptors enhances synaptic transmission at the Drosophila neuromuscular junction. Neuropharmacology 33: 645-657.

Received August 18, 2005; accepted in revised form November 4, 2005.

\section{Learning \& Memory}

www.learnmem.org 


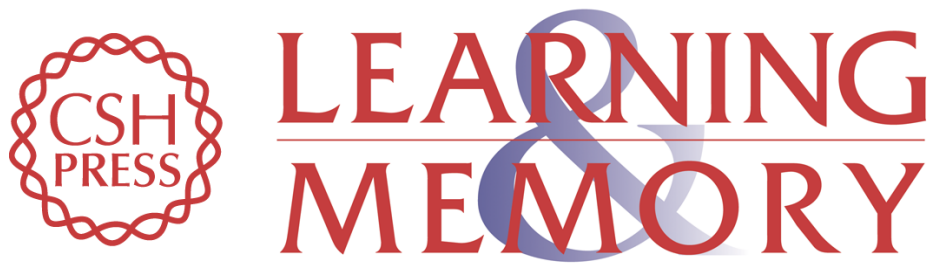

\section{Critical role of nitric oxide-cGMP cascade in the formation of cAMP-dependent long-term memory}

Yukihisa Matsumoto, Sae Unoki, Hitoshi Aonuma, et al.

Learn. Mem. 2006, 13:

Access the most recent version at doi:10.1101//m.130506

References This article cites 57 articles, 19 of which can be accessed free at: http://learnmem.cshlp.org/content/13/1/35.full.htmI\#ref-list-1

License

Email Alerting

Receive free email alerts when new articles cite this article - sign up in the box at the Service top right corner of the article or click here. 